\title{
Multiple OXPHOS Deficiency in the Liver, Kidney, Heart, and Skeletal Muscle of Patients With Methylmalonic Aciduria and Propionic Aciduria
}

\author{
YVES DE KEYZER, VASSILI VALAYANNOPOULOS, JEAN-FRANÇOIS BENOIST, FRÉDÉRIC BATTEUX, \\ FLORENCE LACAILLE, LAURENCE HUBERT, DOMINIQUE CHRÉTIEN, BERNADETTE CHADEFEAUX-VEKEMANS, \\ PATRICK NIAUDET, GUY TOUATI, ARNOLD MUNNICH, AND PASCALE DE LONLAY
}

\author{
Metabolic Unit and Paediatric Department [V.V., F.L., P.N., G.T., P.L.] and Biochemistry Department [B.C.-V.], Hopital Necker-Enfants \\ Malades; INSERM-U781 [Y.K., L.H., D.C., A.M., P.L.], University Paris Descartes, 75743 Paris, France; Biochemistry Department [J.-F.B.], \\ Hopital Robert-Debré, 75019 Paris, France; Laboratoire d'immunologie EA1833 [F.B.], University Paris Descartes, 75014 Paris, France
}

\begin{abstract}
We investigated respiratory chain (RC), tricarboxylic acid cycle (TCA) enzyme activities, and oxidative stress in the tissues of six patients with organic aciduria (OA) presenting various severe complications to further document the role of mitochondrial OXPHOS dysfunction in the development of complications. Two children with propionic acidemia (PA), presenting a severe cardiomyopathy, and four with methylmalonic aciduria (MMA), who developed a neurologic disease (3/4) and renal failure (2/4), were followed. We measured RC and TCA cycle enzyme activity in patient tissues and assessed oxidative metabolism in fibroblasts in vitro. Various RC deficiencies were found in tissues of patients with PA and MMA. TCA cycle enzyme activities were normal when investigated and reactive oxygen species were decreased as well as detoxifying systems activities in the two patients tested. In conclusion, mitochondrial dysfunction was found in all investigated tissues of six patients with organic acidemia presenting with severe complications. Reactive oxygen species production and detoxification were decreased in fibroblast primary cultures. Our results bring further support for a role of secondary respiratory deficiency in the development of late multiorgan complications of these diseases. (Pediatr Res 66: 91-95, 2009)
\end{abstract}

$\mathrm{P}$ ropionic aciduria (PA) and methylmalonic aciduria (MMA) are severe inborn errors of the catabolism of branched-chain amino acids and odd-numbered chain fatty acids. PA results from mutations in the $P C C A$ or $P C C B$ genes, encoding the $\alpha$ and $\beta$ subunits of propionyl-CoA carboxylase, respectively, which converts propionyl-CoA into methylmalonyl-CoA. MMA is caused by mutations in the MUT gene, encoding the methylmalonyl-CoA mutase (MCM), or more rarely in genes encoding the coenzyme adenosylcobalamin of MCM. MCM converts methylmalonyl-CoA into succinylCoA, an intermediate of the tricarboxylic acid cycle (TCA) cycle, which generates NADH used by the mitochondrial respiratory chain $(\mathrm{RC})$.

Organic acidurias (OA) usually present as an acute metabolic distress at birth, when the enzymatic deficiency is complete, or later in life, when the deficiency is less severe. As

Received November 25, 2008; accepted February 28, 2009.

Correspondence: Yves de Keyzer, Ph.D., INSERM U781, Hôpital Necker-Enfants Malades, 149 rue de Sèvres, 75743 Paris cedex 15, France; e-mail: yves.dekeyzer@inserm.fr

Supported by the Fondation Lejeune and Association Française contre la Myopathie (subvention No. 13387) propionate is produced by the catabolism of branched-chain amino acids, fatty acids with a carbon odd-chain and the intestinal flora, the treatment is based on a strict low-protein diet associated with a sufficient caloric intake, carnitine, and antibiotics. However, despite the therapeutic improvements of the last 20 y (1), the overall outcome of patients with OA remains unsatisfying: reports are increasing of long-term complications, such as neurologic disorders by degeneration of the basal ganglia (2), progressive renal failure (3), acute pancreatitis $(4,5)$, and cardiomyopathy (6). It is commonly believed that 2-methylcitrate, methylmalonic acid (MA), and other accumulated metabolites derived from propionate inhibit some mitochondrial enzymes and are toxic on multiple tissues. However, current treatments designed to limit the accumulation of toxins remain insufficient. Recently, a secondary RC deficiency was suggested to be the cause of these complications, as elevated levels of lactate were found in globi pallidi of patients (7), and mitochondrial dysfunction was confirmed in a few patients $(6,8,9)$. Here, we report on six patients, with OA, two PA, and four MMA, in whom we found multiple RC deficiencies in several tissues, including skeletal muscle, liver, heart, and kidney.

\section{PATIENTS AND METHODS}

Patients. Six patients, two with PA and four with MMA were followed up at Necker-Enfants Malades Hospital. Their treatment consisted on a lowprotein diet adapted to individual tolerance, combined with an amino acids mixture devoid of propionate precursors, and, except for patient 1 , a nocturnal enteral feeding. All patients received carnitine $(50-100 \mathrm{mg} / \mathrm{kg} / \mathrm{d})$ and antibiotics: metronidazole $(20 \mathrm{mg} / \mathrm{kg} / \mathrm{d})$ alone or alternate (trimethoprim $30 \mathrm{mg} /$ $\mathrm{kg} / \mathrm{d}$, sulfamethoxazole $20 \mathrm{mg} / \mathrm{kg} / \mathrm{d}$, and amoxycillin $50 \mathrm{mg} / \mathrm{kg} / \mathrm{d}$ ). Vitamin B12 supplementation was unsuccessful in all patients with MMA.

The study protocol was approved by the Ethics Committee of Necker-Enfants malades Hospital, and patients' parents gave written informed consent.

Molecular genetic diagnostic. Mutations in the PCCA, PCCB, or MUT genes were identified after PCR amplification of patient DNA and dideoxynucleotide sequencing using the BigDye terminator cycle sequencing kit (Applied Biosystems, Foster City, CA) and analysis with ABI Prism 3100 DNA sequencer.

Respiratory chain investigation. Tissue biopsies were obtained with informed consent and mitochondrial RC activities were spectrophotometrically measured according to standard procedures (10).

\footnotetext{
Abbreviations: MA, methylmalonic acid; MCM, methylmalonyl-CoA mutase; MMA, methylmalonyl aciduria; OA, organic aciduria; PA, propionic acidemia; RC, respiratory chain; TCA, tricarboxylic acid
} 
TCA cycle enzyme activities investigation. The activities of citrate synthase, succinate CoA ligase (GDP-forming or ADP-forming), succinate dehydrogenase, and fumarase were measured according to published methods (11).

Oxidative stress. Oxidative metabolism was assessed on skin fibroblast cultures in 96-well plates seeded with $2 \times 10^{4}$ cells/well as described previously (12). Superoxide anion $\left(\mathrm{O}_{2}^{--}\right)$and hydrogen peroxide $\left(\mathrm{H}_{2} \mathrm{O}_{2}\right)$ production as well as reduced glutathione concentration were estimated with fluorescent probes (Molecular Probes, Eugene, OR). Results were normalized for the number of living cells as determined at the end of the experiments by the crystal violet staining assay. Superoxide dismutase and catalase activities were evaluated as previously described $(13,14)$. Enzyme activities were normalized for the amount of proteins in each sample.

Patient 1. At 10 mo of age, PA was diagnosed in this girl because of hypotonia and mild mental retardation. She carefully followed her treatment and only three episodes of metabolic distress were recorded over $6 \mathrm{y}$ of follow-up. The good neurologic development allowed a normal school education. At the age of $6 \mathrm{y}$ while the metabolic condition was considered very satisfactory, routine echocardiography revealed a slightly dilated left ventricle and a shortening fraction of $26 \%$. At this time, biochemical investigations showed low excretion of metabolites (Table 1). Plasma levels of free and total carnitine were normal (31 and $86 \mu \mathrm{M}$, respectively). A treatment with an angiotensin-converting enzyme inhibitor and then a $\beta$ blocker was rapidly initiated. This severe heart involvement was considered as an indication for orthotopic liver transplantation (OLT), which was performed at the age of $6 \mathrm{y}$ 8 mo. The child was able to return home 2 mo after the successful transplantation. Heart function improved quickly thereafter allowing the discontinuation of all heart failure treatments within 1 mo after the OLT. One year later, the heart function was normal. Molecular analysis identified two heterozygote mutations in the $P C C B$ gene.

Patient 2. PA was diagnosed in this $14-\mathrm{y}$-old girl at 1 -mo old because of failure to thrive and hypotonia. The course of the disease had been marked by 21 episodes of metabolic distress triggered by benign viral diseases and asthma attacks in the first $10 \mathrm{y}$ of life. At the age of 8 , she presented a severe global heart failure without any metabolic distress (Table 1) or obvious triggering factor. Echocardiography showed a severely hypokinetic dilated heart, with a left ventricular end diastolic diameter of $59 \mathrm{~mm}$, a shortening fraction reduced to $17 \%$, and a moderate functional mitral incompetence. Treatment with angiotensin-converting enzyme inhibitor and diuretics rapidly improved the clinical signs of heart failure. An endomyocardial biopsy revealed focal fibrotic lesions. Currently, patient 2 still has a chronic heart failure compensated by angiotensin-converting enzyme inhibitor, diuretics, $\beta$ blockers, and digoxin. The cardiac condition is too severe to propose an OLT.

Patient 3. MMA was diagnosed in this boy at the age of 2 mo because of failure to thrive and vomiting, followed by a coma. The course of the disease was marked by a mild psychomotor retardation since the age of $1 \mathrm{y}$ and three hospitalized metabolic attacks between 2.5- and 4-y old. At the age of $2.5 \mathrm{y}$, peripheral and axial hypotonia was noted and brain T2-weighted MRI displayed hyperintensities in the periventricular white matter and both hippocampus. During the first 2 y of life, biochemical investigations showed a cumulative level of MA at 3.7 (mean level) and 2.80 (median level) mmol/ mmol creatinine in urine, which increased to 6.14 and 5.34, respectively, during the following $3 \mathrm{rd}$ and 4 th $\mathrm{y}$. At 5-y-old, choreoathetosis developed leading to the inability to walk. T2-weighted brain MRI displayed hyperintensities in both pallidi associated with a high peak of lactate on spectroscopy. However, at that time and during the year after, his levels of urinary MA were stable at 3.93 (mean) and 4.36 (median) $\mathrm{mmol} / \mathrm{mmol}$ creatinine. Renal function was normal until the age of $6 \mathrm{y}$ with an inulin clearance at 70 $\mathrm{mL} / \mathrm{min} / 1.73 \mathrm{~m}^{2}$.
Patient 4. MMA was diagnosed in this boy at $3 \mathrm{~d}$ of age old because of failure to thrive, vomiting, and metabolic acidosis. The course of the disease during the first $6 \mathrm{y}$ of age was marked by three hospitalized metabolic attacks while the neurologic development was normal. During these $6 \mathrm{y}$, biochemical investigations showed cumulative levels of MA between 4.7 and $8.7 \mathrm{mmol} /$ mmol creatinine per year (mean) and between 5 and $8.7 \mathrm{mmol} / \mathrm{mmol}$ creatinine per year (median) (Table 1). Renal function was normal. At age $6 \mathrm{y}$, growth retardation was noted associated with increased mean levels of MA in urine $(11.946 \mathrm{mmol} / \mathrm{mmol}$ creatinine). At $7 \mathrm{y}$ old, during a gastroenteritis, he presented a severe metabolic acidosis $(\mathrm{pH}=7.04$, bicarbonate $3 \mathrm{mM}$, ketones bodies elevated in urine) with mild hyperammonemia $(80 \mu \mathrm{M})$, elevated plasma lactate $(5.8 \mathrm{mM})$, and increased plasma lipase (1510 UI/L) but normal liver tests. Organic acids chromatography showed a very low excretion of MA in plasma $(72 \mu \mathrm{M})$ and in urine $(1.2 \mathrm{mmol} / \mathrm{mmol}$ creatinine $)$. Despite an intensive treatment with hemodialysis, glucolipidic parenteral infusion, and L-carnitine, general condition worsened with coma and large tremors. The patient died from this acute necrotizing pancreatitis complicated with multiorgan failure and disseminated intravascular coagulation. His T2-weighted brain MRI displayed hyperintensities in both pallidi.

Patient 5. Patient 5 has been recently reported because of an unusual follow-up of his MMA diagnosed at the age of $10 \mathrm{~d}$ (15). The course of the disease was marked by several hospitalized metabolic attacks during the first $6 \mathrm{y}$ of age, a persistent hepatomegaly since the age of $4 \mathrm{y}$, a Leigh syndrome at $6 \mathrm{y}$ old associated with a peak of lactate at spectroscopy, and renal insufficiency requiring dialysis at the age of $8.7 \mathrm{y}$ and renal transplantation at the age of $9.5 \mathrm{y}$. However, at $11 \mathrm{y}$ of age, general condition dramatically worsened with the discovery of a hepatocarcinoma and the patient died. Biochemical investigations before the age of $8 \mathrm{y}$ showed a cumulative level of urinary MA at 3.69 $\mathrm{mmol} / \mathrm{mmol}$ creatinine (mean) and 4.7 (median).

Patient 6. This boy presented with failure to thrive, vomiting, and growth retardation since birth, worsening after food diversification. The diagnosis of MMA was made at 2 y old after a coma with metabolic acidosis. At this time, the patient presented with severe psychomotor retardation, extrapyramidal syndrome, spastic tetraplegia, and inability to walk. The brain MRI showed T2 hyperintensities of both pallidi and occipital white matter abnormalities. Mean and median levels of urinary MA were elevated during the $2 \mathrm{y}$ after the diagnosis (12.212 and $35.100 \mathrm{mmol} / \mathrm{mmol}$ creatinine respectively), then they improved around $5 \mathrm{mmol} / \mathrm{mmol}$ creatinine. Only one metabolic decompensation occurred at age $6.5 \mathrm{y}$. At $14-\mathrm{y}$-old, renal insufficiency was diagnosed with inulin clearance at $69 \mathrm{~mL} / \mathrm{min} / 1.73 \mathrm{~m}^{2}$ (plasma creatinine $118 \mu \mathrm{M}$ ). The interest of renal transplantation was discussed at age 16 because of his very bad general condition.

\section{RESULTS}

Enzymatic and molecular diagnostic. An undetectable MCM or propionyl-CoA carboxylase activity was observed on cultured skin fibroblasts with or without cofactor in all patients. No stimulation of the residual activity by cobalamin was observed in the propionate incorporation test, defining a mut (0) phenotype for patients with MMA. Two mutations in the MUT gene were identified in three patients with MMA (Table 1). All mutations have been reported to be responsible for mut (0) phenotype (16). Two mutations in the PCCB gene

Table 1. Clinical and biological data of the patients

\begin{tabular}{|c|c|c|c|c|c|c|c|c|}
\hline \multirow[b]{2}{*}{ Patient } & \multirow[b]{2}{*}{ Diagnosis } & \multirow[b]{2}{*}{ Onset age } & \multirow[b]{2}{*}{$\begin{array}{l}\text { Molecular } \\
\text { diagnosis }\end{array}$} & \multicolumn{5}{|c|}{ Urinary metabolites ( $\mu \mathrm{mol} / \mathrm{mmol}$ creatinine) } \\
\hline & & & & $\begin{array}{l}\text { 3-Hydroxy- } \\
\text { propionate }\end{array}$ & $\begin{array}{l}\text { Propionyl } \\
\text { glycine }\end{array}$ & Tiglyglycine & 2-Methylcitrate & $\begin{array}{c}\text { Methylmalonic } \\
\text { acid }\end{array}$ \\
\hline 1 & $\mathrm{PA}$ & $10 \mathrm{mo}$ & $\begin{array}{l}\mathrm{R} 376 \mathrm{C} / \mathrm{H} 258 \mathrm{R} \\
\quad(\mathrm{PCCB} \text { gene })\end{array}$ & 22 & 10 & 7 & 100 & ND \\
\hline 2 & $\mathrm{PA}$ & $1 \mathrm{mo}$ & ND & 34 & 20 & 78 & 99 & ND \\
\hline 3 & MMA & $2 \mathrm{mo}$ & R474X/R511X & ND & ND & ND & ND & $3.7 \times 10^{3}$ \\
\hline 4 & MMA & $3 \mathrm{~d}$ & ND & ND & ND & ND & ND & 4.7 to $8.7 \times 10^{3}$ \\
\hline 5 & MMA & $10 \mathrm{~d}$ & A191E/N219Y & ND & ND & ND & ND & $3.7 \times 10^{3}$ \\
\hline 6 & MMA & $2 \mathrm{y}$ & [1876-1888del13] & ND & ND & ND & ND & $12.2 \times 10^{3}$ \\
\hline
\end{tabular}

Results are expressed as $\mu \mathrm{mol} / \mathrm{mmol}$ creatinine.

ND, not done. 
Table 2. Spectrophotometric analysis of mitochondrial respiratory chain and citrate synthase activities

\begin{tabular}{|c|c|c|c|c|c|c|c|}
\hline \multirow[b]{2}{*}{ Tissue } & \multirow{2}{*}{$\begin{array}{c}\text { Muscle } \\
\text { patient } 1\end{array}$} & \multirow{2}{*}{$\begin{array}{c}\text { Muscle } \\
\text { mitochondria } \\
\text { patient } 3\end{array}$} & \multicolumn{2}{|r|}{ Liver } & \multicolumn{2}{|r|}{ Heart } & \multirow{2}{*}{$\begin{array}{l}\text { Kidney } \\
\text { patient } 5\end{array}$} \\
\hline & & & Patient 1 & Patient 4 & Patient 1 & Patient 2 & \\
\hline NQR (CI) & $42(18 \pm 5)$ & $82(65 \pm 16)$ & 36 & $12(24 \pm 5)$ & 126 & $108(64 \pm 14)$ & $9(65 \pm 1)$ \\
\hline SQDR (CII) & $61(33 \pm 8)$ & $98(99 \pm 25)$ & 249 & $189(143 \pm 20)$ & 136 & $86(106 \pm 21)$ & $29(106 \pm 6)$ \\
\hline QCCR (CIII) & $405(349 \pm 74)$ & $1606(1310 \pm 308)$ & 295 & $267(380 \pm 62)$ & 726 & $-(1104 \pm 214)$ & $86(507 \pm 125)$ \\
\hline COX (CIV) & $243(148 \pm 38)$ & $716(728 \pm 226)$ & 180 & $94(184 \pm 30)$ & 808 & $646(583 \pm 126)$ & $67(213 \pm 32)$ \\
\hline ATPase $(\mathrm{CV})$ & $159(151 \pm 41)$ & $387(324 \pm 81)$ & 156 & $93(94 \pm 20)$ & 360 & $-(199 \pm 41)$ & $-(116 \pm 41)$ \\
\hline SCCR (CII + CIII $)$ & $47(27 \pm 8)$ & $255(230 \pm 62)$ & 81 & $70(71 \pm 14)$ & 133 & $130(155 \pm 33)$ & $20(74 \pm 25)$ \\
\hline $\mathrm{CS}$ & $257(103 \pm 23)$ & $-(378 \pm 89)$ & 104 & $93(61 \pm 9)$ & 308 & $265(309 \pm 56)$ & $43(94 \pm 10)$ \\
\hline NQR/CS & $0.16(0.17 \pm 0.03)$ & -1 & 0.35 & $\mathbf{0 . 1 3}(0.40 \pm 0.07)$ & 0.41 & $0.41(0.20 \pm 0.03)$ & $\mathbf{0 . 2 1}(0.61 \pm 0.07)$ \\
\hline SQDR/CS & $0.24(0.30 \pm 0.04)$ & -- & 2.39 & $2.03(2.16 \pm 0.29)$ & 0.44 & $0.32(0.34 \pm 0.05)$ & $\mathbf{0 . 6 7}(1.17 \pm 0.08)$ \\
\hline $\mathrm{QCCR} / \mathrm{CS}$ & $\mathbf{1 . 6}(2.9 \pm 0.4)$ & -- & 2.8 & $\mathbf{2 . 9}(6.1 \pm 0.9)$ & 2.4 & $-(3.3 \pm 0.4)$ & $\mathbf{2 . 0}(5.19 \pm 0.14)$ \\
\hline $\mathrm{COX} / \mathrm{CS}$ & $\mathbf{0 . 9}(1.6 \pm 0.2)$ & -- & 1.7 & $\mathbf{1 . 0}(3.0 \pm 0.4)$ & 2.6 & $2.4(1.7 \pm 0.2)$ & $1.56(2.17 \pm 0.16)$ \\
\hline ATPase/CS & $0.62(0.59 \pm 0.13)$ & -- & 1.50 & $\mathbf{1 . 0 0}(1.69 \pm 0.28)$ & 1.17 & $-(0.66 \pm 0.09)$ & - \\
\hline
\end{tabular}

Results are expressed as nmole/min/mg protein. Abnormal values are indicated in bold characters. Control values are shown in parentheses (mean $\pm \mathrm{SD}, n \geq 20$ ).

NQR (CI), NADH ubiquinone reductase (complex I); SQDR (CII), succinate ubiquinone DCPIP reductase (complex II); QCCR (CIII), ubiquinol cytochrome c reductase (complex III); COX (CIV), cytochrome c oxidase (complex IV); NCCR, NADH cytochrome c reductase (complex I + III); SCCR, succinate cytochrome c reductase (complex II + III); CS, citrate synthase.

Table 3. Spectrofluorimetric analysis of ROS levels and detoxifying enzymes activities

\begin{tabular}{clccccc}
\hline & \multicolumn{3}{c}{ Reactive oxygen species } & & \multicolumn{2}{c}{ Detoxyfying enzymes } \\
\cline { 2 - 3 } Patients & Nitric oxide & Superoxide anions & Hydrogen peroxide & & SOD & Catalase \\
\hline Control & $0.159 \pm 0.004$ & $0.141 \pm 0.004$ & $22.33 \pm 0.93$ & & $3.72 \pm 0.33$ & $1.90 \pm 0.21$ \\
1 & $0.093 \pm 0.009^{*}$ & $0.074 \pm 0.007^{*}$ & $15.92 \pm 1.92 \dagger$ & & $0.48 \pm 0.05^{*}$ & $0.88 \pm 0.09^{*}$ \\
3 & $0.147 \pm 0.003$ & $0.075 \pm 0.07^{*}$ & $20.76 \pm 0.50$ & & $2.73 \pm 0.22 \dagger$ & $1.16 \pm 0.12 \dagger$ \\
\hline
\end{tabular}

Fibroblasts $\left(2 \times 10^{4} /\right.$ well $)$ were incubated with $5 \mu \mathrm{M} / \mathrm{L}$ DHE or H2-DCFDA for $30 \mathrm{~min}$, washed, and fluorescence intensity (FI) was recorded every hour for $5 \mathrm{~h}$. The levels of $\mathrm{O}_{2}^{\bullet-}$ and of $\mathrm{H}_{2} \mathrm{O}_{2}$ were calculated as follows: ROS rate (arbitrary units/min/10 cells) = FI (arbitrary units) at T300 min - FI at T0/300 $\mathrm{min} /$ number of adherent cells. Results are expressed as arbitrary units $/ \mathrm{min} / 10^{6}$ cells.

$*<0.001$.

$\dagger<0.02$.

SOD, superoxide dismutase.

were identified in one patient with PA (Table 1). The DNA could not be analyzed for the other patients.

Respiratory chain deficiency. An OXPHOS deficiency was found in the liver (multiple deficiencies, patient 4; CIII and CIV deficiency, patient 1 ), the skeletal muscle (CIII + CIV deficiency, patient 1), the heart (CIII deficiency, patient 1), and the kidney (multiple deficiencies, patients 5) (Table 2). When reported to citrate synthase activity, OXPHOS activities were low excluding an unspecific global decrease of mitochondria activity because of poor preservation of the sample or an advanced stage of organ failure. The skeletal muscle of patient 3 showed a normal OXPHOS activity in vitro but histochemical analysis showed predominance of type I muscle fibers, atrophy of type II fibers, and subsarcolemmal aggregates of mitochondria, consistent with RC deficiency. Normal OXPHOS activities were found in fibroblasts (patient 1) and lymphocytes (patient 5).

TCA cycle enzyme activities investigation. The activity of the citrate synthase was in the normal range or above in all patients' tissues except patient 5 (Table 2). Succinyl-CoA ligase (GDP-forming or ADP-forming), succinate dehydrogenase, and fumarase activities were normal in the liver of the two investigated patients ( 1 and 4, data not shown).

Oxidative stress. Nitric oxide, superoxide anions, and hydrogen peroxide production were decreased in patient 1 fibroblasts
(Table 3) and superoxide anions production was decreased in patient 3. Superoxide dismutase and catalase activities were also significantly decreased in both patients (Table 3), but not the levels of reduced glutathion (data not shown).

\section{DISCUSSION}

We report here on mitochondrial $\mathrm{RC}$ deficiencies in four patients with MMA and two with PA, suffering from neurologic, renal, and cardiac complications. Our results support the hypothesis of OXPHOS impairment as an additional mechanism to intoxication to explain renal insufficiency and the energetic-dependent cardiomyopathy reversible after liver transplantation. A secondary involvement of the RC in patients with MMA and PA was suggested as the cause of these late complications, as lactate was found elevated in globi pallidi of affected patients (7). As previously mentioned, this hypothesis was confirmed in a few patients' tissues with PA (9) as well as here, in our patients, displaying mitochondrial dysfunction.

The basal ganglia abnormalities have been attributed to the accumulation of neurotoxic organic acids (17) as several metabolites deriving from alternative oxidation pathways of propionyl-CoA are known to inhibit in vitro the energy metabolic pathways $(18,19)$. 2-Methylcitrate is a potent inhibitor 
of the TCA cycle enzymes citrate synthase, aconitase, and isocitrate dehydrogenase; MA inhibits pyruvate carboxylase; and propionyl-CoA inhibits CoA-dependent enzymes, such as pyruvate dehydrogenase, succinyl-CoA synthetase, and ATP citrate lyase (18). Moreover, the important accumulation of these CoA-linked metabolites may deplete the cellular pool of available $\mathrm{CoA}$ and thus impair most of the mitochondrial energy pathways. However, no TCA enzyme defect was found in vitro. It should be noted that in vitro enzymatic assays provide optimal conditions in which we measure the maximal activity a tissue can reach, whereas in vivo the conditions may be less than optimal. Impaired energy metabolism was observed in some of our patients despite a good metabolic control, suggesting a different mechanism from accumulation of toxic compounds. Indeed, dilated cardiomyopathy, which was observed in $23 \%$ of our series of patients with PA (Romano, $\mathrm{S}$ et al. in preparation) developed independently of the metabolic status, like in patient 1 who presented a lateonset disease at 10 mo of age, after suffering very few metabolic distresses and excreting little metabolites in urines. Neurologic symptoms may also appear despite a good metabolic control in PA (20), or in MMA mut (-) patients with partial enzyme deficiency (7). Similarly, tubulo-interstitial nephropathy leading to renal insufficiency is also frequent whatever the mut phenotype (2). Thus, the precise mechanisms underlying complication development remain unclear, even if a role of toxic metabolites is probable (21). Apart from metabolic enzyme inhibition, MA was recently shown to inhibit the mitochondrial dicarboxylate carrier in vitro (22) suggesting that it may alter the transport of various dicarboxylic acids into mitochondria including TCA cycle intermediates (23). This mechanism may thus result in further energy metabolism deficiency and contribute to the global OXPHOS deficiency in the patients' tissues. Interestingly, kidney proximal tubule cells are involved in the uptake of urinary excreted dicarboxylic and tricarboxylic TCA cycle intermediates. Their transport into mitochondria may be of importance to provide adequate metabolite supply to the TCA cycle and fulfill the high level of energy production needed to carry out normal kidney function (24) In addition, because propionyl-CoA metabolism normally contributes to succinyl-CoA pool, even as a minor source, its deficiency may also decrease TCA activity. In this view, it is worth noting that succinyl-CoA pools are much lower than those of other TCA cycle intermediates and play an important role in anaplerosis of the cycle (25). The actual flux of TCA cycle metabolites could not be measured in our patients because of the limited availability of tissues. The decreased reactive oxygen species (ROS) production in the fibroblasts of two patients also suggests that, in vivo, the RC functions below its maximal capacity, even though OXPHOS activities were found normal in fibroblasts when measured in vitro, i.e., with optimal supply of substrates. Such a decrease is a possible consequence of reduced TCA flux. The concomitant decrease of detoxifying enzymes indicates that decreased ROS production was not because of increased detoxification activities and further supports the hypothesis of reduced ROS generation by the RC. On the opposite, oxidative stress has been suggested as another pathogenic mechanism in patients with PA or MMA (26). Recently, in a large series of fibroblasts derived from patients with MMA, Richard et al. (27) reported variable levels of both ROS and detoxification enzymes ranging from normal to clearly increased levels $(8,28)$. Although the contribution of oxidative stress in PA and MMA remains unclear, our results indicate that it is not systematically increased and suggest that OXPHOS deficiency may develop independently of abnormal free radical generation. Finally, mtDNA depletion now recognized as an important cause of RC deficiency, has been found associated to metabolic diseases including succinyl-CoA synthase (SCS) defects, which also lead to MA and propionate-derived metabolites accumulation (29-32). Interestingly, moderate ( $\sim 50 \%)$ mtDNA depletion was detected in the liver of PA patient 1 (not shown) but not in another patient with MMA and could not be studied in the other patients. The frequency of depletion and its importance in patients with OA remains to be established.

Liver and renal transplantation are well-known alternative therapeutic options, which provide an increase of enzymatic activity and allow the patients to follow normal diet. We observed a dramatic regression of cardiomyopathy in one patient with PA after liver transplantation. However, neither liver nor renal transplantation (33-37) seem to prevent neurologic complications in many MMA and PA, a complication most likely related to the blood-brain barrier (38). Thus, the potential of anaplerotic substrates to sustain the TCA cycle flux in patients with MMA and PA could represent another therapeutic option to prevent long-term energetic complications. This kind of approach has been successfully used in patients with pyruvate carboxylase (39) and fatty acid oxidation defects (25), although it should be noted that triheptanoin, the substrate given in these studies, is totally contraindicated in patients with PA and MMA as it would bring an increase in propionyl-CoA.

In conclusion, major long-term complications may occur in patients with OA despite optimal dietary and medical treatment, secondary to OXPHOS deficiency. Cardiomyopathy was reversed in one patient with PA after liver transplantation. The low levels of toxic metabolites measured in most patients suggest that several mechanisms may contribute to energy impairment in addition to the so-called intoxication.

Acknowledgment. We thank JM Saudubray, N Boddaert, I Desguerre, B Chabrol, and MA Cosson for their contribution.

\section{REFERENCES}

1. Touati G, Valayannopoulos V, Mention K, de Lonlay P, Jouvet P, Depondt E, Assoun M, Souberbielle JC, Rabier D, Ogier de Baulny H, Saudubray JM 2006 Methylmalonic and propionic acidurias: management without or with a few supplements of specific amino acid mixture. J Inherit Metab Dis 29:288-298

2. Dionisi-Vici C, Deodato F, Roschinger W, Rhead W, Wilcken B 2006 'Classical' organic acidurias, propionic aciduria, methylmalonic aciduria and isovaleric aciduria: long-term outcome and effects of expanded newborn screening using tandem mass spectrometry. J Inherit Metab Dis 29:383-389

3. Walter JH, Michalski A, Wilson WM, Leonard JV, Barratt TM, Dillon MJ 1989 Chronic renal failure in methylmalonic acidaemia. Eur J Pediatr 148:344-348

4. Kahler SG, Sherwood WG, Woolf D, Lawless ST, Zaritsky A, Bonham J, Taylor CJ, Clarke JT, Durie P, Leonard JV 1994 Pancreatitis in patients with organic acidemias. J Pediatr 124:239-243

5. Burlina AB, Dionisi-Vici C, Piovan S, Saponara I, Bartuli A, Sabetta G, Zacchello F 1995 Acute pancreatitis in propionic acidaemia. J Inherit Metab Dis 18:169-172 
6. Mardach R, Verity MA, Cederbaum SD 2005 Clinical, pathological, and biochemical studies in a patient with propionic acidemia and fatal cardiomyopathy. Mol Genet Metab 85:286-290

7. Burlina AP, Manara R, Calderone M, Catuogno S, Burlina AB 2003 Diffusionweighted imaging in the assessment of neurological damage in patients with methylmalonic aciduria. J Inherit Metab Dis 26:417-422

8. Chandler RJ, Zerfas PM, Shanske S, Sloan J, Hoffmann V, Dimauro S, Venditti CP 2009 Mitochondrial dysfunction in mut methylmalonic acidemia. FASEB J 23:1252-1261

9. Schwab MA, Sauer SW, Okun JG, Nijtmans LG, Rodenburg RJ, van den Heuvel LP, Drose S, Brandt U, Hoffmann GF, Ter Laak H, Kolker S, Smeitink JA 2006 Secondary mitochondrial dysfunction in propionic aciduria: a pathogenic role for endogenous mitochondrial toxins. Biochem J 398:107-112

10. Rustin P, Chretien D, Bourgeron T, Gerard B, Rotig A, Saudubray J, Munnich A 1994 Biochemical and molecular investigations in respiratory chain deficiencies. Clin Chim Acta 228:35-51

11. Blomstrand E, Radegran G, Saltin B 1997 Maximum rate of oxygen uptake by human skeletal muscle in relation to maximal activities of enzymes in the Krebs cycle. J Physiol 501:455-460

12. Alexandre J, Batteux F, Nicco C, Chereau C, Laurent A, Guillevin L, Weill B, Goldwasser F 2006 Accumulation of hydrogen peroxide is an early and crucial step fo paclitaxel-induced cancer cell death both in vitro and in vivo. Int J Cancer 119:41-48

13. Aebi H 1984 Catalase in vitro. Methods Enzymol 105:121-126

14. Beauchamp C, Fridovich I 1971 Superoxide dismutase: improved assays and an assay applicable to acrylamide gels. Anal Biochem 44:276-287

15. Cosson MA, Touati G, Lacaille F, Valayannnopoulos V, Guyot C, Guest G, Verkarre V, Chrétien D, Rabier D, Munnich A, Benoist JF, de Keyzer Y, Niaudet P, de Lonlay P 2008 Liver hepatocarcinoma and multiple OXPHOS deficiency in the follow-up of a patient with methylmalonic aciduria. Mol Genet Metab 95:107-109

16. Acquaviva C, Benoist JF, Pereira S, Callebaut I, Koskas T, Porquet D, Elion J 2005 Molecular basis of methylmalonyl-CoA mutase apoenzyme defect in 40 European patients affected by mut(o) and mut- forms of methylmalonic acidemia: identification of 29 novel mutations in the MUT gene. Hum Mutat 25:167-176

17. Cheema-Dhadli S, Leznoff CC, Halperin ML 1975 Effect of 2-methylcitrate on citrate metabolism: implications for the management of patients with propionic acidemia and methylmalonic aciduria. Pediatr Res 9:905-908

18. Brusque AM, Borba Rosa R, Schuck PF, Dalcin KB, Ribeiro CA, Silva CG, Wannmacher CM, Dutra-Filho CS, Wyse AT, Briones P, Wajner M 2002 Inhibition of the mitochondrial respiratory chain complex activities in rat cerebral cortex by methylmalonic acid. Neurochem Int 40:593-601

19. Okun JG, Horster F, Farkas LM, Feyh P, Hinz A, Sauer S, Hoffmann GF, Unsicker K, Mayatepek E, Kolker S 2002 Neurodegeneration in methylmalonic aciduria involves inhibition of complex II and the tricarboxylic acid cycle, and synergistically acting excitotoxicity. J Biol Chem 277:14674-14680

20. Haas RH, Marsden DL, Capistrano-Estrada S, Hamilton R, Grafe MR, Wong W, Nyhan WL 1995 Acute basal ganglia infarction in propionic acidemia. J Child Neurol 10:18-22

21. Schmitt CP, Mehls O, Trefz FK, Horster F, Weber TL, Kolker S 2004 Reversible end-stage renal disease in an adolescent patient with methylmalonic aciduria. Pediat Nephrol 19:1182-1184

22. Mirandola SR, Melo DR, Schuck PF, Ferreira GC, Wajner M, Castilho RF 2008 Methylmalonate inhibits succinate-supported oxygen consumption by interfering with mitochondrial succinate uptake. J Inherit Metab Dis 31:44-54
23. Morath MA, Okun JG, Muller IB, Sauer SW, Horster F, Hoffmann GF, Kolker S 2008 Neurodegeneration and chronic renal failure in methylmalonic aciduria-a pathophysiological approach. J Inherit Metab Dis 31:35-43

24. Burckhardt BC, Burckhardt G 2003 Transport of organic anions across the basolateral membrane of proximal tubule cells. Rev Physiol Biochem Pharmacol 146:95158

25. Brunengraber H, Roe CR 2006 Anaplerotic molecules: current and future. J Inheri Metab Dis 29:327-331

26. Treacy E, Arbour L, Chessex P, Graham G, Kasprzak L, Casey K, Bell L, Mamer O, Scriver CR 1996 Glutathione deficiency as a complication of methylmalonic acidemia: Response to high doses of ascorbate. J Pediatr 129:445-448

27. Richard E, Alvarez-Barrientos A, Perez B, Desviat LR, Ugarte M 2007 Methylmalonic acidaemia leads to increased production of reactive oxygen species and induction of apoptosis through the mitochondrial/caspase pathway. J Patho 213:453-461

28. Wajner M, Coelho JC 1997 Neurological dysfunction in methylmalonic acidaemia is probably related to the inhibitory effect of methylmalonate on brain energy production. J Inherit Metab Dis 20:761-768

29. Carrozzo R, Dionisi-Vici C, Steuerwald U, Lucioli S, Deodato F, Di Giandomenico S, Bertini E, Franke B, Kluijtmans LA, Meschini MC, Rizzo C, Piemonte F, Rodenburg R, Santer R, Santorelli FM, van Rooij A, Vermunt-de Koning D, Morava E, Wevers RA 2007 SUCLA2 mutations are associated with mild methylmalonic aciduria, Leigh-like encephalomyopathy, dystonia and deafness. Brain 130:862-874

30. Ostergaard E, Christensen E, Kristensen E, Mogensen B, Duno M, Shoubridge EA, Wibrand F 2007 Deficiency of the alpha subunit of succinate-coenzyme. A ligase causes fatal infantile lactic acidosis with mitochondrial DNA depletion. Am J Hum Genet 81:383-387

31. Ostergaard E, Hansen FJ, Sorensen N, Duno M, Vissing J, Larsen PL, Faeroe O, Thorgrimsson S, Wibrand F, Christensen E, Schwartz M 2007 Mitochondrial encephalomyopathy with elevated methylmalonic acid is caused by SUCLA2 mutations. Brain 130:853-861

32. Elpeleg O, Miller C, Hershkovitz E, Bitner-Glindzicz M, Bondi-Rubinstein G, Rahman S, Pagnamenta A, Eshhar S, Saada A 2005 Deficiency of the ADP-forming succinyl-CoA synthase activity is associated with encephalomyopathy and mitochondrial DNA depletion. Am J Hum Genet 76:1081-1086

33. Barshes NR, Vanatta JM, Patel AJ, Carter BA, O'Mahony CA, Karpen SJ, Goss JA 2006 Evaluation and management of patients with propionic acidemia undergoing liver transplantation: a comprehensive review. Pediatr Transplant 10:773-781

34. Kaplan P, Ficicioglu C, Mazur AT, Palmieri MJ, Berry GT 2006 Liver transplantation is not curative for methylmalonic acidopathy caused by methylmalonyl-CoA mutase deficiency. Mol Genet Metab 88:322-326

35. Lubrano R, Elli M, Rossi M, Travasso E, Raggi C, Barsotti P, Carducci C, Berloco P 2007 Renal transplant in methylmalonic acidemia: could it be the best option? Report on a case at 10 years and review of the literature. Pediatr Nephrol 22:1209-1214

36. Nagarajan S, Enns GM, Millan MT, Winter S, Sarwal MM 2005 Management of methylmalonic acidaemia by combined liver-kidney transplantation. J Inherit Metab Dis 28:517-524

37. Nyhan WL, Gargus JJ, Boyle K, Selby R, Koch R 2002 Progressive neurologic disability in methylmalonic acidemia despite transplantation of the liver. Eur J Pediatr 161:377-379

38. Kolker S, Okun JG 2005 Methylmalonic acid-an endogenous toxin? Cell Mol Life Sci 62:621-624

39. Mochel F, DeLonlay P, Touati G, Brunengraber H, Kinman RP, Rabier D, Roe CR, Saudubray JM 2005 Pyruvate carboxylase deficiency: clinical and biochemical response to anaplerotic diet therapy. Mol Genet Metab 84:305-312 